УДК 316.343

$10.17213 / 2075-2067-2021-3-39-45$

\title{
ТРАНСФОРМАЦИЯ СЕМЕЙНЫХ ЦЕННОСТЕЙ НА СОВРЕМЕННОМ ЭТАПЕ
}

\author{
(C) 2021 г. 3. Х. Коблева
}

\section{Майкопский государственный технологический университет, г. Майкоп, Россия}

Цель исследования: изучить основные механизмы трансформации иенностей современной семьи; рассмотреть и раскрыть характеристику семьи как особого сочииального института; выявить в современном обществе основные соииокультурные процессы, оказывающие влияние на семейную жизнь и ее уклад; провести сочиологический анализ основных причин и механизмов семейных трансформаций на современном этапе. $B$ соответствии с ичелью исследования были поставлены и решены следующие задачи: изучить семью в качестве объекта сочиологического исследования, выявить основные формы и характеристики семейных иенностей на современном этапе, рассмотреть основные проблемь семьи в современном российском обществе.

Методологическая база исследования. Эмпирической базой исследования являются труды отечественных исследователей. Методологическую основу статьи составил системно-изенностный подход, а также методы сравнения и наблюдения.

Актуальность темы исследования обусловлена появлением серьезного научного интереса к проблемам трансформаџии семейных ценностей в условиях трансформации современного общества.

Результаты исследования. Доказано, что происходящие в современном российском обществе процессы оказывают воздействие на семейную жизнь, ее уклад и, следовательно, формируют сочиальный портрет современного государства. Все более значимой становится социокультурная направленность современной семьи, связанная с сохранением и повышением иенности семейного образа жизни в интересах устойчивого развития социума и человечества в целом. Рассмотренный анализ основных причин и механизмов семейных трансформаций способствует обоснованию возможности их регулирования и значительного расширения знания о семье.

Перспективы исследования: продолжить теоретико-методологические исследования проблемы трансформации семейных ценностей в современном обществе.

Ключевые слова: семья; семейные иенности; трансформация; институт семьи; социокультурные иченности; многодетная семья; неполная семья; общество.

\section{TRANSFORMATION OF FAMILY VALUES AT THE PRESENT STAGE}

\section{(C) 2021 Z. H. Kobleva}

\section{Maikop State Technological University, Maikop, Russia}

The purpose of the study: to study the main mechanisms of transformation of the values of the modern family; to consider and reveal the characteristics of the family as a special social institution; to identify the main socio-cultural processes in modern society that affect family life and its way of life; to conduct a sociological analysis of the main causes and mechanisms of family 
transformations at the present stage. In accordance with the purpose of the study, the following tasks were set and solved: to study the family as an object of sociological research, identify the main forms and characteristics of family values at the present stage, to consider the main problems of the family in modern Russian society.

Methodological basis of the study. The empirical basis of the study is the works of domestic researchers. The methodological basis of the article is a system-value approach, as well as methods of comparison and observation.

The relevance of the research topic is due to the emergence of a serious scientific interest in the problems of the transformation of family values in the context of the transformation of modern society.

The results of the study. It is proved that the processes taking place in modern Russian society have an impact on family life, its way of life and, consequently, form a social portrait of the modern state. The socio-cultural orientation of the modern family is becoming more and more important, which is associated with preserving and increasing the value of the family lifestyle in the interests of sustainable development of society and humanity as a whole. The analysis of the main causes and mechanisms of family transformations contributes to the justification of the possibility of their regulation and a significant expansion of knowledge about the family.

Research prospects: to continue theoretical and methodological research of the problem of transformation of family values in modern society.

Key words: family; family values; transformation; family institution; sociocultural values; large family; incomplete family; society.

Социальные трансформации, происходящие в настоящее время в российском обществе, нашли свое отражение в ценностной основе всего социума, оказывая огромное влияние на семью как основной социальный институт любого общества. В этой связи появляются новые формы и модели социального взаимодействия в структуре социальных связей.

Отметим, что ценностная характеристика семьи является важным звеном в становлении и развитии социальной структуры любого общества. Являясь составной частью общества, семья проходит через разные периоды своего существования. В настоящее время появляются новые формы семейных отношений, отражающие современную социально-политическую ситуацию в стране.

Современная семья представляет особый исследовательский интерес со стороны различных гуманитарных наук: философии, социологии, культурологии, психологии и других, где проблема семейных ценностей является одной из центральных. Прежде всего, это объясняется тем, что ценности являются фундаментальной основой духовного развития личности и общества.
Проблему взаимовлияния ценностнонормативных систем личности определил в своих исследованиях Э. Дюркгейм, согласно которому система ценностей общества представляет собой совокупность ценностных представлений отдельных людей. Дюркгейм считал, что шкала ценностей оказывается независимой от переменных и индивидуальных оценок индивидов. Кроме того, он указывал на необходимость построения иерархии ценностей. Он выделял следующие ценности: экономические, религиозные, нравственные, метафизические, эстетические. Усвоенные из этих систем ценности выступают в качестве коллективных и индивидуальных ориентиров действий людей [1].

Категории «идеал» и «эталон», определяющие тот или иной уровень культуры, представлены в исследованиях П.А. Сорокина. В этом смысле социологическая интерпретация ценности перекликается с ее культурологическими и философскими определениями [2].

С середины 1960-х гг. в отечественной науке стали появляться исследования ценностей и ценностных ориентаций в теоретических работах А.Г. Здравомыслова, В.А. Ядова, 
Г.М. Андреевой и др. Основные характеристики личности, в том числе в среде разных социальных групп и общностей, занимают ведущее место в исследовательских работах [3].

Формирование иерархии ценностей и ценностных ориентаций общества происходило во все времена, каждый период имел свои особенности и характеристики социокультурных ценностей и правил поведения людей, но самой незыблемой и актуальной остается ценность семьи и семейных традиций.

Семья представляет собой особую общность людей, на которой базируется само государство. Выполняя самые разные функции, семья как социальный институт выступает индикатором развития всего общества, раскрывая определенные проблемы и в других сферах жизни.

Основная социальная сущность семьи заключается в ее особой роли между личностью и государством, выполнении функции трансляции семейных ценностей в обществе. Характеризуя семью с точки зрения общечеловеческих ценностей, можно сказать, что формирование социокультурных ценностей семьи должно было бы стать основной задачей для развития общества.

Однако в настоящее время происходит переход от традиционных форм семейных ценностей к новым формам и моделям поведения в обществе. Следует отметить, что институт семьи переживает определенный кризис, связанный с трансформацией традиционных семейных ценностей, которая выражается в распаде многих современных семей по причине невыполнения своих обязанностей, в переходе к внесемейному образу жизни и различным формам гражданского брака. Известно, что кризис семейных ценностей влечет за собой серьезные последствия для института семьи в целом, вплоть до угрозы исчезновения. Подобные явления сегодня актуальны для европейских государств, где происходит размывание традиционных ценностей семьи и уже официально разрешены однополые браки.

Серьезный процесс трансформации семейных ценностей в настоящее время происходит и в России, где наблюдается отрицательный естественный прирост населения, распад семьи как основного социального института общества, беспрецедентный рост детской беспризорности и социального сиротства, приведшие к серьезным социальным последствиям. Подобный процесс дестабилизации нашего общества, несомненно, связан с социально-политическими изменениями в стране, характеризующимися кризисом духовно-нравственных и традиционных ценностей.

Отметим, что количество современных семей, которые не в состоянии выполнять свои родительские обязанности по воспитанию детей, с каждым годом растет. Как следствие - появление такого социального явления, как «социальное сиротство» при живых родителях, которые не справляются или не хотят выполнять свои обязанности по воспитанию детей. Характерными особенностями этого явления становится полное отчуждение детей от семьи и родителей, потеря постоянного места жительства и существование в местах, не пригодных для жилья. В этих условиях дети, предоставленные сами себе, вынуждены заниматься воровством, попрошайничеством, чтобы добыть себе средства для жизни.

Заметим, что рост беспризорности как социальное явление в истории был связан с потрясениями в обществе: голодом, войнами, стихийными бедствиями, которые влекут за собой рост количества детей-сирот, оставшихся без попечения родителей. Беспризорность в обществе несет в себе серьезную опасность в виде наркомании и алкоголизма, а также способствует росту правонарушений в этой среде.

Лишенные средств к элементарному существованию, беспризорные дети часто становятся объектом повышенного внимания со стороны различных криминальных структур, которые используют их в своих противозаконных целях - в торговле алкогольной и табачной продукцией, распространении наркотиков, занятии проституцией и т.д.

Следствием такого поведения детей является отсутствие систематического обучения в школе среди сверстников. Анализируя причины детской беспризорности, следует прежде всего отметить кризисные явления в семье и рост количества семейных разводов в стране, которые подрывают нравственные устои в обществе и несут определенную опасность для жизнедеятельности государства в целом. Проблема детской беспризорности, 
алкоголизм, наркомания являются серьезной угрозой для будущего нашей страны и важной проблемой современности, требующей теоретического исследования и осмысления.

Одной из тенденций современного общества является увеличивающееся число неполных семей, где ребенок вынужден воспитываться после развода родителей одним из них. В результате воспитательные функции и нравственные устои таких семей ослабевают либо полностью утрачиваются. К основным причинам этих явлений следует отнести семейные конфликты, которые сопровождаются насилием и жестокостью к детям. Вступление в новый брак одного из родителей, с которым проживает ребенок, также становится причиной конфликтной ситуации в семье и побега детей из этой обстановки.

Усиление занятости родителей, вынужденных совмещать несколько рабочих мест, чтобы обеспечить существование членам семьи, перегруженность домашним трудом изза отсутствия материальных средств на пользование услугами сферы быта сокращает возможность общения с детьми, совместных занятий с ними, увеличивает риск детской беспризорности [4].

Еще одной серьезной проблемой современного общества является рождение внебрачных детей. Отсутствие у родителей желания вступать в официальный брак и растить детей вне брака серьезно подрывает традиционные семейные ценности в нашем обществе. Количество детей, рожденных вне брака, в России с каждым годом растет, при этом многие родители объясняют подобные факты кризисом института семьи и проблемами материального характера.

Как показывает практика, увеличение количества внебрачных детей в современном обществе связано с лояльным отношением к таким семьям и детям, что было раньше неприемлемым для нашего традиционного общества.

Существенно изменилось отношение самих женщин к институту брака, в данном контексте женщина все чаще принимает решение родить ребенка исключительно «для себя». Как правило, эта категория женщин имеет высокий уровень материального достатка, который позволяет им растить ребенка в условиях неполной семьи, объясняя этот факт построением своей личной карьеры и отсутствием времени на создание полноценных семейных отношений. Поэтому создание своей собственной, хотя и неполной, семьи серьезно повышает уровень самооценки таких женщин, укрепляет авторитет на работе, способствует более высокому положению в обществе и успешной самореализации ее личности.

Как показывают статистические данные, в период с 2015 по 2019 годы в России продолжается рост внебрачных семей и сокращение количества официальных браков [5].

Следует отметить, что жизнь человека вне семьи и семейных ценностей во многом объясняется причиной изменения во взглядах людей на семейные ценности, формы и модели современной семьи. Для многих это пример современных западных ценностей семьи с правом свободы выбора в семейных отношениях, вплоть до однополых браков.

Сегодня существуют семьи, которым свойственны различные социальные проблемы, называются они малообеспеченными семьями. К категории таких семей можно отнести неполные семьи, семьи, имеющие детей-инвалидов, а также многодетные семьи. В неполных семьях наряду с материальными трудностями возникают и серьезные психологические проблемы, где ребенок чувствует обиду и свою вину в распаде семьи, что впоследствии формирует чувство собственной неполноценности этого ребенка, которое может сопровождать всю его сознательную жизнь. Во многих случаях, имея за плечами печальный опыт своих родителей, эти дети стремятся создать и сохранить любой ценой свою собственную семью и семейные ценности.

Особое внимание заслуживают многодетные семьи, которые являются наименее обеспеченной социальной категорией в обществе. Количество детей в таких семьях напрямую связано с уровнем благосостояния такой семьи и возможностью удовлетворения элементарных потребностей семьи.

В конкретных социально-экономических условиях нашей страны с ростом цен на товары народного потребления у таких семей отмечаются крайне ограниченные возможности в самых необходимых предметах: одежде, обуви, школьно-письменных принадлежностях. Творческое развитие детей или занятия 
в спортивных секциях в большинстве случаев невозможны из-за ограниченности семейного бюджета и материальных средств, которыми располагает конкретная семья. Особенности жизнедеятельности многодетной семьи предполагают множество проблем, с которыми она сталкивается в жизни, и общую социальную проблематику, имеющую свои специфические характеристики в сравнении с другими семьями. К их числу можно отнести формирование у детей заниженной самооценки и представления о собственной значимости, что не может не сказаться на их будущей жизни [6]. В таких семьях дети часто остаются без внимания родителей и, предоставленные сами себе, большую часть времени проводят на улице со сверстниками, которые оказались в аналогичной жизненной ситуации, условиях сложного психологического климата в семье.

Одной из актуальных проблем современных многодетных семей является процесс получения достойного образования. По причине отсутствия материальных возможностей семьи получение образования в таких семьях чаще всего ограничено. У родителей недостаточно времени, чтобы уделять должное внимание к процессу образования детей, а оплачивать услуги репетиторов они не в состоянии.

В настоящее время существуют меры государственной поддержки для многодетных семей, в том числе и в области образования: предоставление льготных мест в учебных заведениях страны с правом бесплатного проживания в общежитии, льготной системы питания и другие. Однако, несмотря на эти меры поддержки со стороны государства, многие многодетные семьи вынуждены самостоятельно решать проблемы образования своих детей, исходя из своих собственных материальных возможностей.

В.Н. Герасимов выделяет проблему реализации прав многодетных семей, считая, что большая часть льгот для многодетных семей в регионах не реализуется и напрямую зависит от состояния платежеспособности бюджетов субъектов Российской Федерации. Такая ситуация не позволяет в полной мере реализовать права детей из многодетных семей на достойные условия жизнедеятельности и всестороннее развитие [7]. Следует также отметить, что во многих многодетных семьях отмечается низкий уровень информационной и правовой грамотности, что значительно снижает уровень своевременного обращения в государственные органы за соответствующей помощью.

В этих условиях необходимо выработать действенные меры государственной семейной политики на федеральном и региональном уровнях с учетом реальных потребностей многодетных семей в нашей стране. Такие меры поддержки должны носить адресный и гарантированный характер.

В настоящее время проблема социальной защиты семьи является одной из приоритетных государственных задач. Как известно, семья, являясь основным социальным институтом общества, выполняет важную воспитательную функцию. Трансформация семейных ценностей в современном обществе влечет за собой серьезные изменения и сбои в воспитании подрастающего поколения, которое впоследствии может испытывать серьезные проблемы и трудности в социальной адаптации, формировании семьи и традиционных семейных ценностей.

Выводы. Современная российская семья переживает сложный период своей жизнедеятельности. Проблемы многодетных и неполных семей, социальное сиротство, детская беспризорность и безработица очень серьезно влияют на существование самого института семьи в нашей стране.

Такая неблагоприятная ситуация способствует формированию негативного отношения к семейным ценностям со стороны детей, у которых еще слабо сформирована психика, и они очень болезненно и агрессивно воспринимают фактор своего семейного неблагополучия. Это в свою очередь становится причиной детской преступности, наркомании и алкоголизма. В целях предупреждения подобных действий необходимы меры поддержки семей, попавших в трудные жизненные условия, направленные на реабилитацию и восстановление семьи.

Таким образом, современное общество ставит под серьезную угрозу факт своего существования, размывая и разрушая семейные ценности. Семья - важнейший институт социализации человека. Уровень семейной социализации связан с социокультурными 
ценностями, традициями и обычаями, а также нравственными установками в обществе, оказывающими существенное влияние на процесс воспитания детей в семье.

Начавшийся процесс трансформации семейных ценностей оказывает серьезное влияние на формирование демографической ситуации в стране в вопросах семейного поведения и воспитания. Сложившуюся демографическую ситуацию в России можно рассматривать с точки зрения основных проблем национальной безопасности страны, поскольку именно семья представляет собой основной институт социальной системы общества, от которой зависит будущее благосостояние нашего государства.

В нынешних социально-экономических условиях, которые не всегда характеризуются определенной стабильностью, молодым людям, вступившим в брак, не всегда удается справиться с трудностями и сложностями семейной жизни. Отсутствие необходимых знаний в области социокультурных и семейных ценностей часто является причиной бракоразводных процессов на современном этапе. Выходом из этой ситуации может стать правильная и грамотная информированность молодежи об особенностях современной семейной жизни, касающихся планирования семьи, рождения и воспитания детей, а также возможность научить молодых людей справляться с семейными трудностями в самых сложных жизненных ситуациях.

Решение актуальных демографических проблем, осуществление государственной семейной политики, создание семейных клубов, поддержка молодежных инициатив, направленные на повышение семейных ценностей, могут способствовать сохранению традиционных семейных ценностей в нашей стране. Поэтому стабильность и благосостояние современного общества сегодня зависят от успешного функционирования института семьи как важного фактора в обеспечении преемственности поколений и сохранении духовнонравственных устоев нашего государства.

\section{Литература}

1. Дюркгейм Э. Ценностные и «реальные» суждения // Соц. исследования. 1991. - №2. - C. 106-114.
2. Сорокин П. Человек. Цивилизация. Общество. - М., 1992. - С. 429.

3. Трансформация социокультурных ценностей населения: социологический анализ: коллективная монография / под редакцией И. В. Шиндряевой; Волгоградский институт управления - филиал ФГБОУ ВО «Российская академия народного хозяйства и государственной службы». — Волгоград: Изд-во Волгоградского института управления - филиала РАНХиГС, 2019. - С. 10.

4. Волгин Н. А. Социальная политика. М.: Экзамен, 2004. - С. 78.

5. Цербакова Е.M. Россия: предварительные демографические итоги 2018 года (часть I) [Электронный ресурс]. - С.13. Режим доступа: http://demoscope.ru/ weekly/2019/0801/Башт01p (Дата обращения: 12.02.2019).

6. Иванова Р. Институт семьи для России // Вестник Института экономики РАН. 2009. — №1. - С. 63-79.

7. Герасимов В.Н. Проблемы современных многодетных семей в России: сравнительный анализ с законодательством стран EC // Российская юстиция. — 2011. — №2. C. 13.

\section{References}

1. Djurkgejm Je. Cennostnye i «real'nye» suzhdenija [Valuable and «real» judgments] // Soc. issledovanija [Social research]. - 1991. №2. - Pp. 106-114.

2. Sorokin P. Chelovek. Civilizacija. Obshhestvo [Man. Civilization. Society]. - Moscow, 1992. - P. 429.

3. Transformacija sociokul'turnyh cennostej naselenija: sociologicheskij analiz: kollektivnaja monografija [Transformation of socio-cultural values of the population: a sociological analysis: a collective monograph] / In I. V. Shindrjaeva (eds.); Volgogradskij institut upravlenija - filial FGBOU VO «Rossijskaja akademija narodnogo hozjajstva i gosudarstvennoj sluzhby» [Volgograd Institute of Management branch of the Russian Academy of National Economy and Public Administration]. - Volgograd: Izd-vo Volgogradskogo instituta upravlenija - filiala RANHiGS, 2019. - P. 10.

4. $\operatorname{Volgin} N$.A. Social'naja politika [Social policy]. — Moscow: Jekzamen, 2004. — P. 78. 
5. Shherbakova E.M. Rossija: predvaritel'nye demograficheskie itogi 2018 goda (chast' I) [Russia: preliminary demographic results of 2018 (part I)] [Jelektronnyj resurs]. — P.13. URL: http://demoscope.ru/weekly/2019/0801/ Башт01p (Date accessed: 12.02.2019).

6. Ivanova R. Institut sem'i dlja Rossii [Institute of Family for Russia] // Vestnik Instituta jekonomiki RAN [Bulletin of the Institute of
Economics of the Russian Academy of Sciences]. — 2009. — №1. - Pp. 63-79.

7. Gerasimov V.N. Problemy sovremennyh mnogodetnyh semej v Rossii: sravnitel'nyj analiz s zakonodatel'stvom stran ES [Problems of modern large families in Russia: comparative analysis with the legislation of the EU countries]// Rossijskaja justicija [Russian Justice]. 2011. — №2. - P. 13.

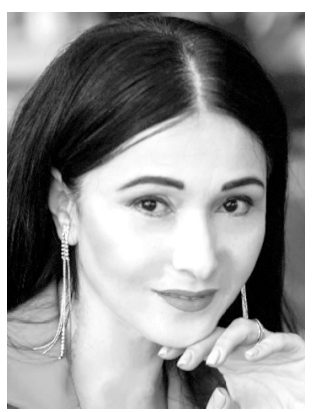

385000, Республика Адыгея, г. Майкоп, ул. Первомайская, 191 191, Pervomayskaya st., 385000, Maykop, Republic of Adygea, Russia E-mail: zureta_01@mail.ru

\begin{abstract}
Коблева Зурет Халидовна - кандидат исторических наук, доцент кафедры философии, социологии и педагогики факультета управления Майкопского государственного технологического университета.
\end{abstract}

Kobleva Zuret Halidovna - Candidate of Historical Sciences, Associate Professor of the Department of Philosophy, Sociology and Pedagogy, Faculty of Management, Maykop State Technological University. 